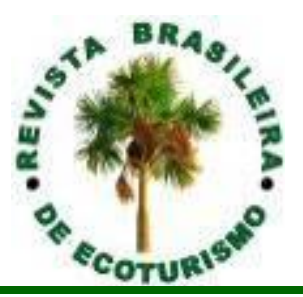

\title{
Pesquisa de satisfação em parques urbanos: um estudo no Parque Ibirapuera (SP)
}

\section{Satisfaction survey in urban parks: a study in Ibirapuera Park (SP, Brazil)}

\author{
Daiane Uinnes Faustino, Reinaldo Miranda de Sá Teles
}

\begin{abstract}
RESUMO: O presente artigo, de caráter exploratório, teve como principal objetivo a análise da satisfação do usuário do Parque lbirapuera, importante atrativo turístico da cidade de São Paulo. O estudo busca compreender a opinião do usuário quanto à infraestrutura e serviços do parque. No decorrer da pesquisa buscou-se, com o referencial teórico, evidenciar a relação entre parques urbanos, qualidade e satisfação, demonstrando que a oferta técnica é parte importante para uma melhor gestão destes ambientes. A fim de mensurar a satisfação de quem frequenta o lbirapuera, foi aplicado um questionário de avaliação a 86 usuários do parque. Os resultados encontrados indicam que o lbirapuera é avaliado como regular pelos usuários contidos na amostra obtida na pesquisa, sendo que a qualidade e quantidade dos espaços culturais é o aspecto mais bem avaliado. As deficiências do parque estão nos banheiros e bebedouros disponíveis para os usuários, assim como nos serviços de estacionamento e alimentação.
\end{abstract}

PALAVRAS CHAVE: Parques Urbanos; Infraestrutura e Serviços; Satisfação; Parque Ibirapuera.

ABSTRACT: The main objective of this exploratory paper was to analyse user satisfaction at lbirapuera Park, an important tourist attraction in the city of São Paulo. The study seeks to understand the user's opinion regarding the park's infrastructure and services. Throughout the research, it sought to highlight with the theoretical framework the relationship between urban parks, quality and satisfaction, demonstrating that the technical offer is an important part for a better management of these environments. In order to measure the satisfaction of those who attend Ibirapuera, 86 users who have already attended the park answered the survey questionnaire. The results found in the sample obtained in the survey indicate that lbirapuera is a park rated as regular, and quality and quantity of cultural spaces were the best-evaluated aspects. The park's deficiencies are in the toilets and drinking fountains available to users, as well as parking and food services.

KEYWORDS: Urban Parks; Infrastructure and Services; Satisfaction; Ibirapuera Park.

Sociedade Brasileira de Ecoturismo. Rua Dona Avelina, 225, Vila Mariana, São Paulo, SP - Brasil.391 E-mail: zneiman@gmail.com; Tel. (55-11) 99195-7685. 


\section{Introdução}

Parques urbanos são áreas verdes de presença comum em ambientes urbanos contemporâneos. A criação de parques consiste na possibilidade de trazer a natureza para dentro dos ambientes densamente urbanizados, numa tentativa de melhoria da qualidade de vida nestes espaços. Os parques, para além dos benefícios já conhecidos na dinâmica da cidade, têm também a possibilidade de serem apropriados por atividades de lazer e, em algumas situações, atividades turísticas. No que diz respeito ao lazer, os parques urbanos são locais que democratizam importantes práticas: a recreação, a contemplação da paisagem e até o envolvimento em serviços ambientais. Os parques urbanos são um dos equipamentos públicos mais importantes da infraestrutura urbana e da infraestrutura verde urbana.

Diante disto, é válido discutir a qualidade da infraestrutura e dos serviços (quando existentes) prestados por estas organizações aos residentes locais e seus visitantes. Qualidade de serviços e infraestrutura adequadas são pontos essenciais para qualquer tipo de atividade que vise 0 atendimento a públicos em geral. Com relação ao turismo, atividade que pertence ao setor terciário da área econômica - mais especificamente ao setor de serviços - , a qualidade de serviços e infraestrutura, assim como a medição da satisfação do viajante, são elementos que ajudam na gestão da qualidade oferecida, isto é, manter o nível de qualidade onde se está satisfeito e melhorar os elementos que geram índices ruins de qualidade. É possível afirmar que o uso público dos parques urbanos está relacionado à sua qualidade como espaço de lazer, pois áreas pouco utilizadas podem se tornar pontos de obsolescência nas cidades, resultando em áreas abandonadas e sem um uso condizente com o seu propósito inicial de criação.

À frente destas questões, o problema de pesquisa que guiou o desenvolvimento desta investigação no Parque Ibirapuera foi formulado a partir da seguinte pergunta: qual o nível de satisfação dos usuários com a infraestrutura e os serviços prestados no âmbito dos parques urbanos? 0 Parque lbirapuera é um local emblemático, pois não é apenas um dos parques mais frequentados da capital paulista, mas também é um dos atrativos turísticos mais visitados da cidade de São Paulo. De acordo com dados da "Pesquisa de Demanda Turística" da cidade de São Paulo (2015), o lbirapuera é o segundo atrativo mais visitado entre quase todos os perfis de turista da cidade (gerais, Brasil, estrangeiros, negócios e lazer), perdendo apenas para a Avenida Paulista.

O objetivo geral desta pesquisa envolveu a mensuração da satisfação dos usuários do Parque Ibirapuera em relação à sua infraestrutura e serviços prestados, sendo que os objetivos específicos são: I) caracterizar o perfil dos usuários; II) caracterizar o perfil da visita dos usuários e III) identificar as áreas mais problemáticas do parque. 


\section{Referencial teórico: à guisa da definição de parques urbanos e suas funções}

Conforme a definição de parques urbanos dada pelo Ministério do Meio Ambiente (s.d., online), parques urbanos são considerados áreas verdes urbanas com função ecológica, estética e de lazer, diferentes, porém, de praças e jardins públicos (parques têm uma extensão maior que ambos). A Secretaria de Infraestrutura e Meio Ambiente do governo do estado de São Paulo (s.d., online) por sua vez dá uma definição mais detalhada, estabelecendo parques urbanos como "grandes espaços verdes localizados em áreas urbanizadas de uso público, com o intuito de propiciar recreação e lazer aos seus visitantes". Também consta nesta definição que estes espaços proporcionam outros tipos de serviços além do ambiental, como serviços culturais e esportivos.

Pode-se notar que a definição dada pelo governo federal é mais genérica que a dada pelo governo estadual de São Paulo, onde este explora mais as funções exercidas por parques urbanos. Porém, também se pode observar uma semelhança entre ambas: a função dos parques urbanos de serem um equipamento de lazer para seus usuários. Essa observação está de acordo com o que afirmam Raimundo e Sarti (2016) sobre os serviços ecossistêmicos (fornecidos pela natureza e indispensáveis à sobrevivência humana) de parques urbanos e demais áreas verdes urbanas: as funções ecossistêmicas de destaque dos parques urbanos são a regulação - de gás, climática, de distúrbio, de oferta de água etc. — e a de informação estética, artística, cultural, histórica etc. - , onde estão as atividades de lazer e turismo.

Segundo Macedo e Sakata (2010, p. 14) a definição de parques urbanos no Brasil nem sempre é precisa. Para esses autores, o parque é "todo espaço de uso público destinado à recreação de massa, qualquer que seja o seu tipo, capaz de incorporar intenções de conservação e cuja estrutura morfológica é auto-suficiente [sic], isto é, não é diretamente influenciada em sua configuração por nenhuma estrutura construída em seu entorno". A partir dessa definição, os autores afirmam que muitos espaços que possuem no nome o termo "parque" não podem ser caracterizados como tal, pois possuem limitações quanto ao aspecto do lazer e/ ou recreação, entrando então em outras definições, como praças de vizinhança.

Num contexto internacional, a Federação Internacional de Parques e Administração de Recreação (2013, p. 2) define parques urbanos como "[...] áreas delimitadas de espaços livres, predominantemente dominadas por vegetação e água, e geralmente reservadas para uso público. Os parques urbanos são em sua maioria maiores, mas também podem ter a forma de 'pocket parks' - com dimensões menores. Parques urbanos são geralmente definidos localmente (pelas autoridades) como parques".

Ao organizar e agrupar os espaços livres quanto às suas funções urbanísticas enquanto da elaboração do Cadastro Municipal de Espaços Livres Urbanos de Ribeirão Preto, Guzzo, Carneiro e Júnior (2006, p. 22) empregam a seguinte definição do que entendem como parques urbanos: 
"espaço livre urbano público com dimensão quase sempre superior à de praças e jardins públicos, destinado ao lazer ativo e contemplativo, à conservação dos recursos naturais e à promoção da melhoria das condições ambientais da cidade". Já Paula (2017, p. 60), ao discorrer sobre alguns conceitos existentes de parques urbanos, concilia-os e adota como definição de parques urbanos o seguinte: "espaços de uso público destinados à recreação da população, estruturados por vegetação e que apresentam estruturas e instalações destinadas a atividades recreativas, esportivas, culturais e/ ou educativas, e cuja estrutura morfológica é autossuficiente com relação ao entorno e com dimensão superior à uma quadra típica urbana".

A despeito da pouca precisão do que são parques urbanos, pode-se verificar, a partir das definições dadas anteriormente, sejam elas dadas por órgãos públicos ou estudiosos da área, que parques urbanos precisam ter alguns elementos para ser assim denominados. Primordialmente, precisa ser um espaço público dentro do perímetro urbano, onde a vegetação é predominante e cujas principais funções são a ecológica-ambiental e a de lazer e recreação, embora possua muitas outras. Cianga e Popescu (2013) afirmam que do ponto de vista turístico as áreas verdes - como os parques e jardins - podem desenvolver uma função turística dentro de um ambiente urbano, já que seus atributos (estéticos, contexto histórico, estilo de design e paisagem) podem atrair turistas e sua extensão (larga e ampla) pode abrigar diferentes atrações.

\section{Infraestrutura}

Infraestrutura é um termo que, no sentido geral, pode ser compreendido como os sistemas físicos básicos de um negócio, região ou nação. Estes sistemas - como o de transporte, de comunicação, elétricos, de água e esgoto - costumam ser dispendiosos, de alto custo de investimento e vitais, numa escala nacional, para a funcionalidade, 0 desenvolvimento econômico e a prosperidade de um país (CHAPPELOW, 2020). Diante disto, infraestrutura pública são os equipamentos, sistemas e estruturas que pertencem e são operados pelo governo, sendo que estes são abertos ao uso público. Infraestrutura também inclui toda a gama de sistemas necessários ao fluxo econômico das atividades diárias e de melhoria do padrão de vida humano. Alguns exemplos de infraestruturas públicas são as infraestruturas de transportes, de águas, de luz e energia, de telecomunicações; de política, educacional, de saúde e recreacional (CFI, s.d., online).

Em cidades, infraestrutura pode ser conceituada como "um sistema técnico de equipamentos e serviços necessários ao desenvolvimento das funções urbanas, podendo estas funções ser vistas sob os aspectos social, econômico e institucional" (ZMITROWICZ; NETO, 1997, n.p.). Os aspectos sociais referem-se à infraestrutura que visa promover condições adequadas de moradia, trabalho, saúde, educação, lazer e segurança. Os aspectos econômicos da infraestrutura são aqueles relacionados às atividades de comercialização de bens e serviços, ou seja, as atividades produtivas. Já a infraestrutura sob 0 aspecto institucional relaciona-se com os meios 
necessários para o desenvolvimento das atividades político-administrativas. Os subsistemas da infraestrutura urbana têm como objetivo final a prestação de um serviço, já que demanda algum tipo de operação e alguma forma de relacionamento com o usuário. Embora o serviço seja o objetivo final destes subsistemas, é importante ressaltar que sempre há a necessidade de investimentos em uma dimensão física, isto é, em bens ou equipamentos (ZMITROWICZ; NETO, 1997).

Outro tipo de infraestrutura presente em cidades é a infraestrutura verde. Este termo é usado para descrever uma rede estrategicamente planejada de áreas naturais e seminaturais com outros recursos ambientais projetados e gerenciados para fornecer uma ampla gama de serviços ecossistêmicos, podendo esta rede ser encontrada em ambientes urbanos e rurais. Em ambientes urbanos, principalmente dentro da cidade e em áreas periurbanas (áreas além dos subúrbios de uma cidade), muitos elementos podem ser parte da infraestrutura verde - por exemplo: parques, jardins, jardins verticais ou telhados verdes - na medida em que são parte de uma rede interconectada e estão fornecendo vários serviços ecossistêmicos (EUROPEAN ENVIRONMENT AGENCY, 2017).

Em escalas menores, como em negócios ou organizações, infraestrutura pode incluir uma variedade de sistemas e estruturas, desde que haja a necessidade de componentes físicos, isto é, componentes que sejam necessários para a operação de um local em específico (CHAPPELOW, 2020). Semelhante definição é apresentada pela Associação Brasileira de Normas Técnicas (ABNT), onde infraestrutura é definida como "o sistema [conjunto de elementos inter-relacionados ou interativos] de instalações, equipamentos e serviços necessários para a operação de uma organização" (2015, p. 19).

Diante do exposto, parques urbanos podem ser compreendidos como espaços públicos que fazem parte da infraestrutura urbana, assim como da infraestrutura verde urbana, voltada às funções sociais - em específico aquelas ligadas ao lazer e recreação - e prestam serviços que garantem a qualidade de vida nas cidades. Portanto, os parques urbanos caracterizam-se como um dos equipamentos mais importantes do espaço público para a prática de lazer, assim como são locais que garantem a qualidade do conforto ambiental urbano (RAIMUNDO; SARTI, 2016).

Os parques urbanos também são parte essencial do direito à cidade, já que satisfazem um conjunto de outros direitos necessários a este último - como o direito ao lazer, à recreação, à paisagem e aos serviços ambientais -, e é dever do poder público satisfazer plenamente estes direitos (SAMPAIO; SAMPAIO; MAGALHÃES, 2016). De acordo com Sampaio, Sampaio e Magalhães (2016, p. 344), "a garantia de acesso e fruição dos seus ativos e a gestão eficiente da sua infraestrutura são elementos necessários para que os parques possam ser efetivos instrumentos da promoção do direito à cidade". Posto isto, é correto afirmar que os parques urbanos precisam de um sistema de instalações, equipamentos e serviços, primordiais para o seu pleno funcionamento como 
espaços de lazer. E este sistema é parte integrante da infraestrutura do parque.

A respeito dos espaços públicos voltados ao lazer, o Serviço Social do Comércio (Sesc) afirma que as pessoas podem se adaptar ao ambiente em que estão, mas é indispensável "dotar um ambiente com os equipamentos adequados, configurando-o de diferentes maneiras capazes de atender às necessidades dos envolvidos", isto é, tornando-o qualificado para o uso social (2013, n.p.). Alguns exemplos de equipamentos apontados pelo Sesc são os elementos informativos (que promovem orientação espacial), facilidade de acesso, hospitalidade, segurança, limpeza, conforto e possibilidades de contemplação da paisagem urbana ou natural.

\section{Serviços}

Conforme consta na ABNT (2015, p. 24), serviço é "a saída [o resultado de um processo] de uma organização, com pelo menos uma atividade necessariamente realizada entre a organização e o cliente". Ainda segundo a ABNT, uma das características de um serviço é a intangibilidade e o seu fornecimento pode envolver uma atividade realizada em um produto tangível ou intangível (um carro a ser reparado ou a entrega da declaração do imposto de renda), a entrega de um produto intangível (entrega de informações num contexto de difusão de conhecimento) ou a criação de um ambiente (em hotéis e restaurantes). De modo geral, um serviço é experimentado pelo cliente.

Kotler e Keller (2012, p. 382) definem os serviços como "qualquer ato ou desempenho, essencialmente intangível, que uma parte pode oferecer a outra e que não resulta na propriedade de nada. A execução de um serviço pode estar ou não ligada a um bem concreto". Os autores ainda afirmam que os serviços possuem quatro características distintivas: intangibilidade, inseparabilidade, variabilidade e perecibilidade.

Como explicado, serviço tem como sua principal característica a intangibilidade e é o resultado de um processo onde há interação entre cliente e organização ${ }^{1}$. Assim, trazendo esse entendimento para os parques urbanos, estes podem oferecer alguns tipos de serviço para quem os frequenta, variando de disponibilidade conforme tamanho e finalidade principal do parque. Também tendo em vista o conceito de infraestrutura, é correto afirmar que é indispensável a um ambiente relacionado ao lazer possuir uma variedade de instalações, equipamentos e serviços que permitam o pleno funcionamento destes espaços.

Embora não se possa fazer uma generalização, com base no levantamento feito pelo site "Áreas Verdes das Cidades" - cujo conteúdo consiste no agrupamento de informações acerca da infraestrutura, serviços e atividades presentes em áreas verdes de São Paulo e outras cidades - e na Classificação Nacional de Atividades Econômicas (CNAE), podem ser identificados três tipos de serviços nos parques urbanos: alimentação, estacionamento e aqueles relacionados às artes, cultura, esportes e recreação (IBGE, s.d., online). 
Os serviços de alimentação são classificados como alojamento e alimentação pela CNAE e têm como característica o preparo das refeições para consumo imediato, com ou sem serviço completo (serviço de mesa). Nesta classificação, que é mais abrangente, estão incluídos os bares, lanchonetes, restaurantes, quiosques, trailers, serviços ambulantes de alimentação dentre outros. Já os serviços de estacionamento são classificados como transporte, armazenagem e correio e são caracterizados pela exploração de edifícios-garagem e parques de estacionamento para veículos, por curta duração.

Quanto às artes, cultura, esportes e recreação, a CNAE usa uma classificação de mesmo nome para as atividades destinadas a satisfazer os interesses culturais, de entretenimento e recreativos da população. Nesta classificação estão a produção e promoção de artes cênicas e espetáculos (inclusive de atuações ao vivo), as bibliotecas, arquivos, museus, jardins zoológicos e botânicos, a exploração de jogos de azar e apostas, as atividades esportivas, de recreação e lazer. Os serviços de alimentação e estacionamento podem estar localizados dentro da área do parque ou em seu entorno imediato (quando não há a disponibilidade no próprio parque). Como o interesse desta pesquisa é a infraestrutura e os serviços dentro dos parques urbanos, os localizados no entorno não serão considerados.

Apesar dos três tipos de serviço descritos serem os mais comuns em parques urbanos, são poucos os parques que os têm em conjunto. Em alguns parques há serviço de alimentação, mas não há estacionamento disponível; em outros há estacionamento, mas não há serviço de alimentação. Com relação ao terceiro tipo de serviço, alguns parques possuem programações culturais durante todo o ano (ÁREAS VERDES DAS CIDADES, s.d.).

Se levarmos em consideração a afirmação do Sesc sobre dotar os espaços públicos de lazer com equipamentos adequados para torná-los qualificados ao uso social, é correto afirmar que dotar os mesmos espaços com serviços complementares a esta infraestrutura também é uma forma de adequá-lo ao uso social e ao atendimento das necessidades dos visitantes, já que é mais um modo de agregar valor ao lugar, ou seja, acrescentar mais um elemento ao conjunto dos benefícios tangíveis e intangíveis proporcionado pelo objeto ou lugar do qual se está desfrutando (KOTLER; KELLER, 2012).

\section{Qualidade}

A qualidade de um produto ou serviço oferecido ao cliente é tema de discussão em diversas áreas do conhecimento, mais notadamente nas áreas de marketing, administração e gestão. Essa preocupação com a percepção de qualidade de um produto ou serviço por um cliente é válida no âmbito do mundo dos negócios e é um dos fatores mais importantes na competitividade de mercado. Conforme conceitos presentes na ABNT (2015, p. 2), a qualidade de produtos e serviços de uma organização é determinada pela: 
[...] capacidade de satisfazer os clientes e pelo impacto pretendido e não intencional nas partes interessadas pertinentes.

A qualidade dos produtos e serviços inclui não apenas sua função e desempenho pretendidos, mas também seu valor percebido e o benefício para o cliente.

Ainda segundo a ABNT (2015, p. 21), qualidade é o "grau em que um conjunto de características inerentes a um objeto satisfaz requisitos" e que uma organização voltada à qualidade promove atitudes, comportamentos e processos que agregam valor através da satisfação das necessidades e expectativas dos clientes e de stakeholders (partes interessadas). Pode-se dizer que uma organização oferece um produto ou serviço de qualidade quando as expectativas dos clientes são atendidas ou superadas, ou seja, a qualidade é a chave para a satisfação dos clientes (KOTLER; KELLER 2012).

A Sociedade Americana de Controle de Qualidade (ASQ) considera qualidade um termo subjetivo, que pode ter diferentes significados dependendo da pessoa ou do setor que o aplica, mas, no uso técnico, ele pode significar "as características de um produto ou serviço que têm sua capacidade de satisfazer necessidades declaradas ou implícitas" e "um produto ou serviço livre de defeitos" (ASQ, s.d., online).

Quando se fala em qualidade no âmbito dos espaços destinados ou apropriados pelo lazer de um ambiente urbano, principalmente dos espaços públicos, pode-se afirmar que um lugar atrativo, ou seja, um local que possua uma boa qualidade espacial, tende a atrair mais pessoas do que um local com a qualidade mais baixa, pois, segundo o Sesc (2013, n.p.), "as pessoas são capazes de reconhecer as diferenças existentes, estimando valores e decidindo pelos espaços mais vantajosos para si". Isto é, na busca por um espaço de lazer, a qualidade é um fator percebido pelas pessoas, sendo que nesse processo elas se direcionam para os locais cuja qualidade é entendida como melhor. Neste sentido, acerca da qualidade nos espaços públicos voltados ao lazer tem-se que:

[...] em espaços públicos de alta qualidade pode acontecer uma ampla gama de atividades, porque o lugar e a situação atraem as pessoas à participação. Indica-se, assim, para a importância do uso do espaço como um pré-requisito para ele ser satisfatório, pois a falta de uso é um dos indicadores de mau desempenho (SESC, 2013, n.p.).

Sampaio, Sampaio e Magalhães (2016) explicam que para uma gestão adequada dos parques urbanos é necessária a criação de indicadores objetivos e mensuráveis de padrão de qualidade. Os autores ainda complementam afirmando que estes padrões devem variar conforme a finalidade principal de cada parque (seja ambiental, de lazer ou ambos). 
Quanto ao monitoramento destes indicadores, os autores alegam que este é fundamental para qualquer tipo de gestão, seja ela pública ou privada.

Diante do que já foi destacado, parques urbanos possuem uma infraestrutura, necessária à sua função de espaço de lazer público, e serviços que complementam o conjunto destes equipamentos. Se a gestão eficiente da infraestrutura destes espaços é um dos elementos para que eles possam promover o direito à cidade, como sugerem Sampaio, Sampaio e Magalhães (2016), então também se pode inferir que a qualidade destes lugares é necessária para que se cumpra plenamente este direito, ou seja, o direito a usar a cidade como um lugar de encontro e reunião, e onde a utilização dos espaços públicos é o aspecto mais importante (EDUCAÇÃO E TERRITÓRIO, 2018).

O direito à cidade é um direito de todos e para garantir que seja atendido outros direitos também precisam ser considerados, como o direito à paisagem, à recreação, ao lazer e aos serviços ambientais proporcionados por áreas verdes urbanas. Os parques urbanos, como espaços públicos voltados ao lazer, democratizam o acesso a esse direito social. A qualidade destes espaços é indispensável em razão de sua utilização pela população, pois a presença de áreas abandonadas e degradadas pode ser associada com o aumento da violência e criminalidade, assim como a desvalorização de imóveis na região (SAMPAIO, SAMPAIO, MAGALHÃES, 2016). E, assim como afirma o Sesc (2013), o pouco uso de um espaço público é um indicador de mau desempenho destes ambientes.

\section{Satisfação}

Para muitas organizações, a satisfação é um conceito chave, pois estas estão focadas em atender as necessidades e exceder as expectativas de seus clientes. Além disso, atrair, reter e entender as necessidades futuras dos clientes e de outras partes interessadas é um dos meios de se atingir um sucesso sustentável (ABNT, 2015). Desta maneira, Kotler e Keller (2012, p. 134) esclarecem que a satisfação é:

[...] o sentimento de prazer ou decepção que resulta da comparação entre o desempenho (ou resultado) percebido de um produto e as expectativas do comprador. Se o desempenho não alcançar as expectativas, o cliente ficará insatisfeito. Se alcançá-las, ele ficará satisfeito. Se o desempenho for além das expectativas, o cliente ficará altamente satisfeito ou encantado.

Ainda segundo Kotler e Keller (2012, p. 134), as avaliações dos clientes quanto ao desempenho de um produto dependem de muitos fatores, sobretudo da relação de fidelidade destes com a marca, portanto, é "comum que os consumidores formem percepções favoráveis sobre um produto de uma marca a qual eles associam com sentimentos positivos". Já para a ASQ (s.d., online), a satisfação de clientes é definida como uma "mensuração que determina quão felizes estão os clientes com as aptidões, serviços e 
produtos de uma empresa", ou seja, é o resultado de entregar um produto ou serviço que atendeu às exigências do cliente.

Para a ABNT (2015, p. 29), satisfação é a "percepção do cliente do grau em que as expectativas do cliente foram atendidas". Há casos em que a expectativa do cliente pode não ser conhecida pela organização até que o produto ou serviço seja entregue, mas mesmo estas expectativas sendo implícitas ou não sendo declaradas, é necessário atendê-las, para alcançar uma alta satisfação do cliente (ABNT, 2015).

Sendo assim, a satisfação do cliente é um fator importante na formação de desejo para experiências e compras futuras. É correto afirmar que satisfação e qualidade estão conectadas: enquanto a primeira é o "gostaria", ou seja, a expectativa com o serviço/produto a ser experimentado, a segunda é o "deveria", isto é, os processos que deveriam ser realizados para resultar na satisfação do cliente (MOSAHAB; MAHAMAD; RAMAYAD, 2010).

A percepção do ambiente de cada indivíduo é dependente das diversas motivações que definem o comportamento de uma pessoa, sendo que este último está direcionado à satisfação das necessidades individuais. Por ser algo subjetivo, a intensidade com que estas necessidades serão atendidas depende de muitos fatores individuais, incluso as características físicas do ambiente construído (SESC, 2013).

Muitas organizações medem diligentemente a forma como seus clientes são tratados, buscando identificar elementos que moldam a satisfação destes com os seus produtos; o resultado deste procedimento é a modificação de operações e ações de marketing da organização para com seus clientes. Desse modo, é essencial que se faça a medição da satisfação dos clientes com regularidade, pois esse é um processo importante para mantê-los, e embora reclamações sejam muitas vezes consideradas como um indicador de uma baixa satisfação, uma baixa frequência delas não significa uma alta satisfação com a organização (KOTLER; KELLER, 2012; ABNT, 2015).

Segundo Rossi e Slongo (1998, p. 102), a pesquisa de satisfação de clientes é "um sistema de administração de informações que continuamente capta a voz do cliente, através da avaliação da performance da empresa a partir do ponto de vista do cliente". Os autores ainda explicam que este tipo de pesquisa mede a qualidade externa ou performance da empresa em seus negócios, dando subsídios para decisões futuras de comercialização e marketing.

A ASQ ainda complementa que informações sobre a satisfação de clientes, incluindo pesquisas e avaliações, podem ajudar a organização nas decisões quanto à melhoria ou mudanças nos seus produtos e serviços. Quanto aos benefícios proporcionados pela pesquisa, podem ser citadas a percepção mais positiva quanto à empresa, informações precisas e atualizadas quanto às necessidades dos clientes, relações de lealdade entre cliente-organização e maior confiança entre ambos (ROSSI; SLONGO, 1998). 
A discussão sobre a qualidade e satisfação de clientes - ou frequentadores, trazendo o conceito para a área ambiental — no âmbito dos parques urbanos é importante, pois estes também são prestadores de serviços. Conhecer o nível de satisfação de frequentadores de parques urbanos com a sua infraestrutura e serviços é importante, pois isto ajuda na gestão da qualidade oferecida, isto é, manter o nível de qualidade onde se está satisfeito e melhorar os elementos que geram índices ruins de qualidade.

\section{Parque Ibirapuera: objeto desta pesquisa}

O Parque Ibirapuera é um parque urbano localizado no município de São Paulo, na subprefeitura de Vila Mariana, distrito de Moema. A subprefeitura de Vila Mariana - onde estão compreendidos os distritos de Moema, Vila Mariana e Saúde — integra a macrorregião Sul 1 de São Paulo e é uma das regiões mais valorizadas da cidade, com diversificação de atividades e investimentos no setor terciário, cultural e equipamentos públicos de saúde e lazer de âmbito regional. A região também possui o segundo melhor Índice de Desenvolvimento Humano Municipal (IDHM) da cidade de São Paulo $(0,9)$ - acima da média municipal —, e seus distritos apresentam níveis altos e médios de atividade econômica (SÃO PAULO, 2016b). A Figura 1 localiza o Parque Ibirapuera no município de São Paulo e no distrito de Moema.

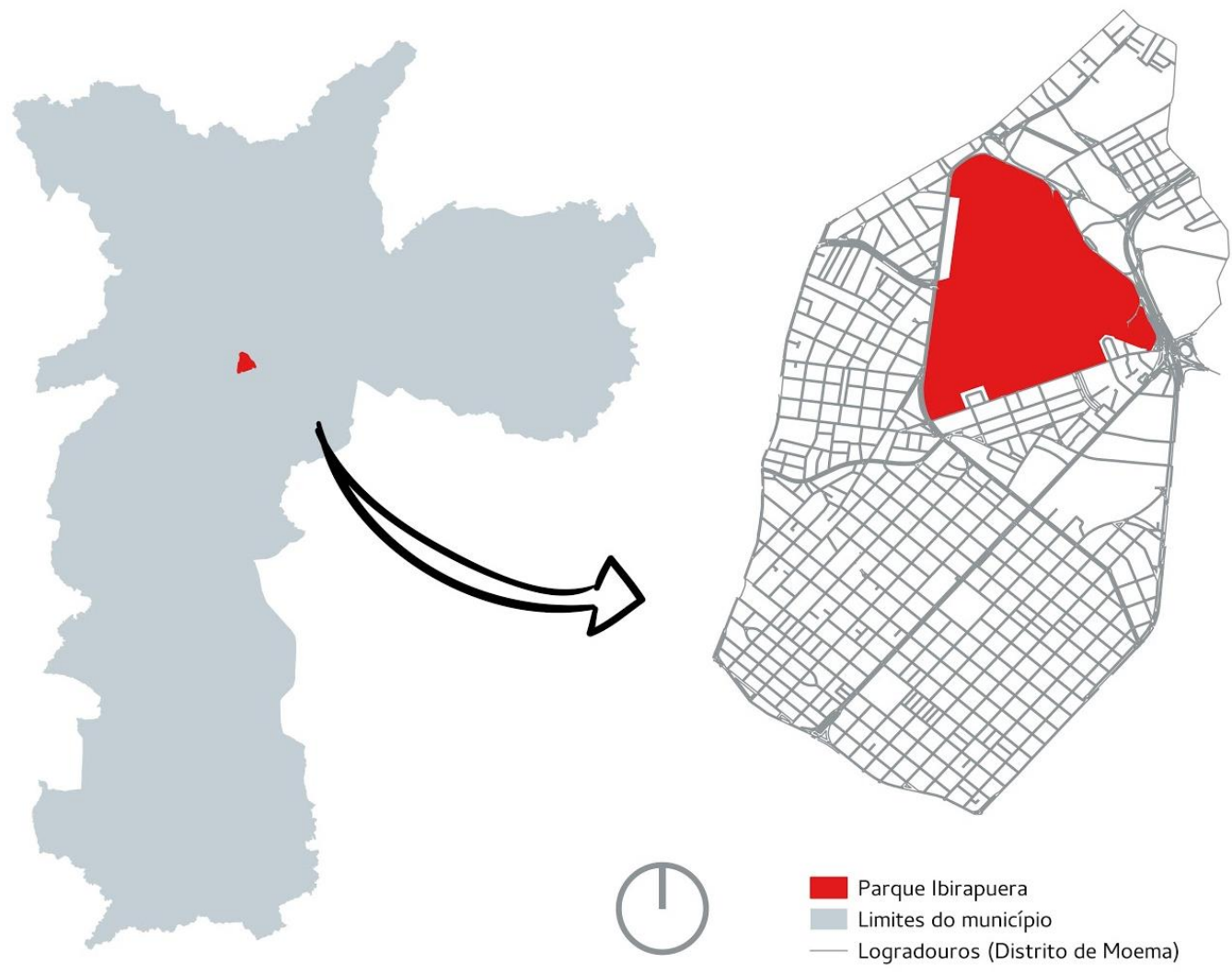

Figura 1: Localização do Parque Ibirapuera no município de São Paulo.

Figure 1: Location of Ibirapuera Park in the City of São Paulo.

Fonte: elaborado pelos autores com dados de Geosampa.

Source: elaborated by the authors with datas from Geosampa. 
O distrito de Moema possui uma população de 83.368 habitantes e é marcado pela presença de bairros-jardim - como Jardim Lusitânia, Vila Paulista, Vila Nova Conceição e Jardim Novo Mundo - , de equipamentos de lazer - como o Parque Ibirapuera - , e de edificações importantes, como o Instituto Biológico, a Assembleia Legislativa, o Círculo Militar e o Museu de Arte Contemporânea (MAC). Os bairros de Moema e Indianópolis, que possuem uma concentração variada de comércio e serviços (como o Shopping Ibirapuera), estão localizados neste distrito. No que se refere aos equipamentos públicos de esporte e lazer, apenas $21,2 \%$ da população que reside em Moema está a mais de $1 \mathrm{~km}$ de uma unidade de esportes e lazer; quanto à área de cultura, praticamente todos os habitantes do distrito possuem acesso próximo a um equipamento público deste tipo (SÃO PAULO, 2016a; SÃO PAULO, 2016b).

O Parque Ibirapuera é um dos equipamentos públicos mais utilizados da cidade de São Paulo - o parque recebe, aproximadamente, 250 mil pessoas por semana — também é considerado um dos principais polos de lazer e cultura da cidade, e o melhor parque urbano da capital, segundo estudo piloto sobre indicadores de parques urbanos elaborado pela Fundação Aron Birmann (FAB), que administra o Parque Villa-Lobos (FAB, 2019; SÃO PAULO, 2019a).

Ademais, o Ibirapuera é importante no cenário turístico de São Paulo. Segundo dados da "Pesquisa de Demanda Turística" (2015) da cidade de São Paulo, o parque é o segundo atrativo mais visitado perdendo apenas para a Avenida Paulista - da capital paulista por quase todos os perfis de turistas (gerais, do Brasil, estrangeiros, negócios, lazer e saúde). O parque também está na lista dos principais atrativos turísticos da cidade, sendo um dos pontos por onde passa o Circular Turismo SP, linha circular de ônibus turístico de São Paulo (SÃO PAULO, 2019b). Dada a importância do Parque Ibirapuera, o que se apresenta nesse artigo enquanto resultado de pesquisa passará pela compreensão da construção e entendimento desse local na perspectiva do uso público para fins de lazer e turismo.

\section{Setores, infraestrutura e serviços oferecidos pelo parque}

Levando em conta a paisagem, a apropriação do espaço pelos usuários e os elementos presentes no parque, o lbirapuera pode ser dividido em dois setores: cultural e ambiental. Os lagos são a referência espacial desta setorização, sendo que no setor cultural estão presentes grande parte das edificações do parque, como a Marquise, os Pavilhões (Culturas Brasileiras, Bienal de São Paulo, Museu Afro), a Oca, o Auditório, a Escola Municipal de Astrofísica e o Planetário (SÃO PAULO, 2019a). No setor ambiental prevalecem os maciços arbóreos e as construções associadas ao serviço ambiental do município, como o Viveiro Municipal Manequinho Lopes, a Universidade Aberta do Meio Ambiente e Cultura da Paz (UMAPAZ) e o Herbário Municipal (SÃO PAULO, 2019a).

Segundo dados do Plano Diretor do Ibirapuera, a infraestrutura do parque se divide em quatro grandes conjuntos: edificações, instalações, equipamentos e grandes espaços abertos. No conjunto de edificações estão 
todos os principais prédios e construções, como o Museu Afro Brasil, o Museu de Arte Moderna (MAM), o Pavilhão Japonês etc. No conjunto de instalações estão reunidos os conjuntos de aparelhos para determinado fim, como sinalização, lanchonetes e sanitários. Já no último conjunto estão os equipamentos necessários à realização de uma determinada atividade, como as quadras esportivas e o playground. As principais infraestruturas do parque podem ser melhor visualizadas na Figura 2.

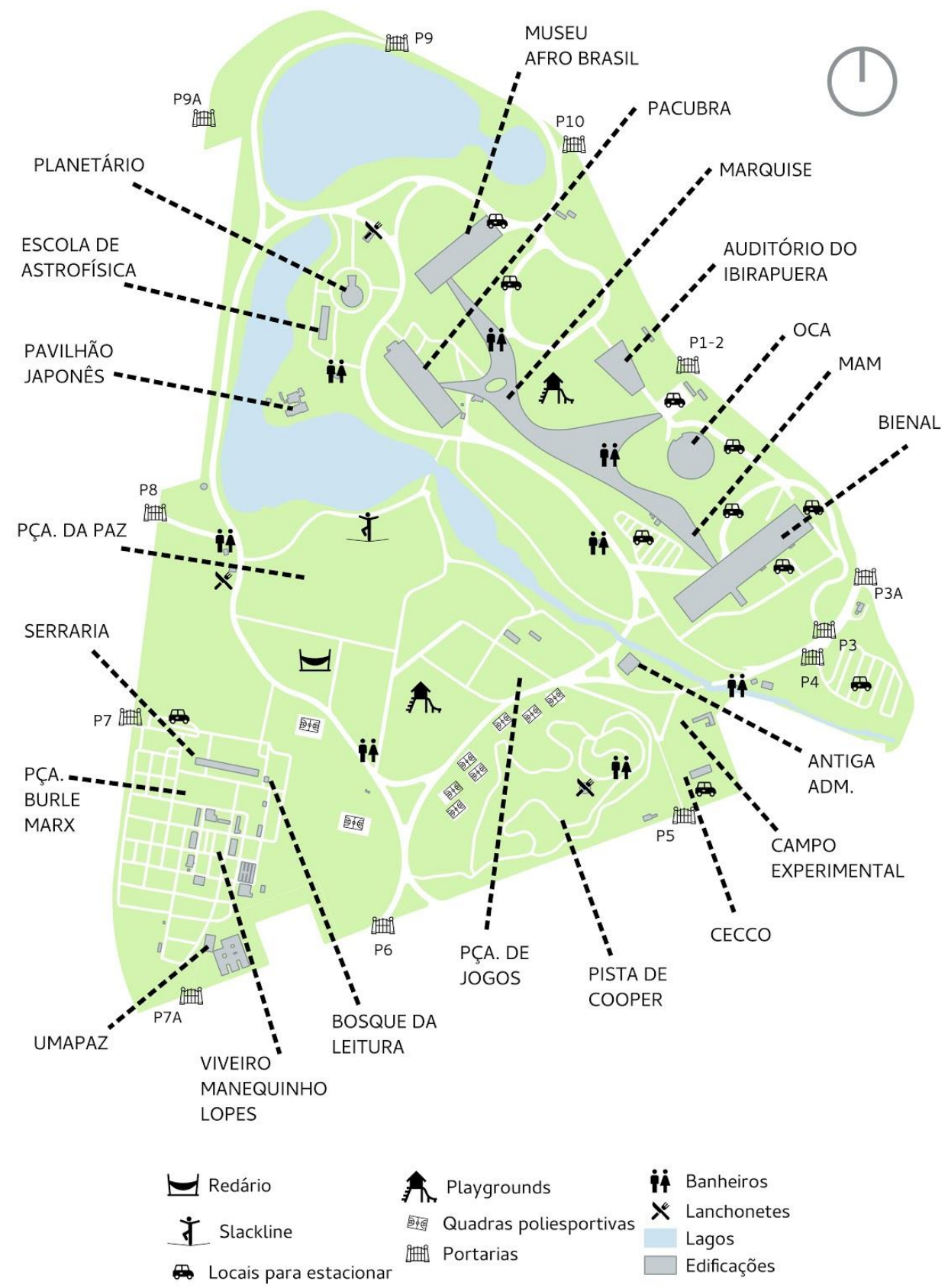

Figura 2: Infraestrutura (com localização aproximada) do Parque Ibirapuera.

Figure 2: Infrastructure (with approximate location) of Ibirapuera Park.

Fonte: elaborado pelos autores com dados de Geosampa, Plano Diretor do Parque Ibirapuera e Google Road.

Source: elaborated by the authors with datas from Geosampa, Ibirapuera Park's Master Plan and Google Road. 
Quanto aos serviços existentes no parque, o Ibirapuera possui serviços de alimentação, de estacionamento e culturais. O parque possui três lanchonetes - uma no setor cultural e duas no setor ambiental -, um restaurante no edifício do MAM, sob a marquise, e diversos ambulantes instalados pela área do parque. Os bolsões de estacionamentos do parque estão localizados no Autorama (portões 3 e 4), na Bienal, MAM, Oca e portão 7, além de vagas em vias próximas à Bienal e Oca; também há vagas operacionais no acesso do portão 10, próximo ao Museu Afro Brasil, utilizadas principalmente em eventos realizados dentro do parque. $O$ estacionamento é pago (Zona Azul) e dá direito a 2 horas renováveis por mais 2 horas. (SÃO PAULO, 2019a; ÁREAS VERDES DAS CIDADES, 2020).

No que se refere aos serviços culturais, o lbirapuera possui várias edificações e espaços que oferecem programações culturais aos seus frequentadores. Segundo a programação de eventos do parque em abril de 2019, ocorrem eventos, exposições e espetáculos nas áreas externas, como na arena da ponte de ferro, na fonte luminosa, no gramado entre a Marquise e o Auditório lbirapuera, no gramado em frente a lanchonete da Praça da Paz, no parquinho próximo ao portão 6 e na Serraria; a UMAPAZ e o Bosque da Leitura também promovem oficinas, palestras, trilhas e minicursos, mediante inscrição. Além das áreas externas também há exposições, oficinas e festivais nas edificações do setor cultural, como na Fundação Bienal, no Museu Afro Brasil e no Pavilhão Japonês, sendo que os dois últimos são pagos (SÃO PAULO, 2019c).

O Parque lbirapuera é considerado o melhor parque urbano da capital paulista, não apenas por ser um dos maiores parques em área de São Paulo - é o terceiro maior da cidade, atrás apenas dos Parques Anhanguera e do Carmo - mas por ser um dos parques que mais recebem investimento em infraestrutura. Por ser muito frequentado, principalmente aos finais de semana, é fácil conseguir parcerias para melhorar seus equipamentos e instalações. Contudo, Sakata (2018) afirma que estas ações são exceções no conjunto de parques públicos, pois o Parque lbirapuera tem uma alta visibilidade e é cobiçado para propaganda e ações de marketing. Embora o objetivo desta pesquisa não seja discutir com profundidade a infraestrutura dos demais parques urbanos da cidade de São Paulo, diante do exposto até aqui, presume-se que a realidade da infraestrutura do lbirapuera não seja a mesma dos demais parques urbanos espalhados por São Paulo, principalmente aqueles localizados em zonas mais periféricas.

\section{Instrumento de coleta de dados e critérios utilizados}

O instrumento de coleta de dados utilizado nesta pesquisa foi o questionário, divulgado entre os dias 04 e 18 de maio de 2020 em redes sociais (Facebook, Instagram e Linkedin) e em aplicativos de mensagens instantâneas (WhatsApp) ${ }^{2}$. Apesar de possuir algumas limitações quando o próprio entrevistado responde às questões, como impedir o conhecimento das circunstâncias em que foi respondido - o que pode ser importante na avaliação da qualidade das respostas - e impedir o auxílio ao respondente 
quando este não entende corretamente as instruções ou perguntas, o questionário possui a vantagem de ser um instrumento de coleta de dados que assegura o anonimato das pessoas e, em formato eletrônico, requer menos recursos para ser aplicado e possibilita atingir um grande número de pessoas (GIL, 2008).

Foram utilizados dois questionários de pesquisa de satisfação como base para a construção do questionário final aplicado nesta pesquisa: o aplicado online pela prefeitura de São Paulo para a elaboração do Plano Municipal de Áreas Protegidas, Áreas Verdes e Espaços Livres (PLANPAVEL) e o aplicado na Pesquisa de Satisfação de Passageiros, realizada pela Secretaria de Aviação Civil (SAC). O primeiro serviu como base para as avaliações relacionadas às características de parques (como limpeza dos lagos e manutenção das áreas verdes) e o último foi utilizado como base para a melhor elaboração das perguntas relacionadas aos serviços (como disponibilidade de vagas no estacionamento e qualidade e quantidade de locais para alimentação), pouco explorados no questionário da prefeitura.

Rossi e Slongo (1998) afirmam que a medição da satisfação do cliente com a empresa deve ser feita com experiências recentes, pois desse modo o cliente tem mais certeza no julgamento dos aspectos positivos e negativos da interação com a empresa. Ainda segundo os autores, seis meses é o período de tempo ideal para fazer esta medição, já que um período maior de tempo pode fazer com que o cliente tenha dificuldades para lembrar com a devida precisão como se deu suas relações com a empresa. Levando esse aspecto em consideração, foi aplicado um filtro no instrumento de coleta de dados, permitindo que somente aqueles que frequentaram o Parque Ibirapuera no ano de 2019 e começo de 2020 (janeiro a março) respondessem ao questionário. Esse procedimento foi adotado porque notou-se, depois de um dia de divulgação do questionário, que um período de seis meses seria muito restritivo para conseguir respostas.

O questionário foi elaborado com 33 perguntas, sendo 32 perguntas fechadas e uma aberta (local de residência). Todas as opções "Outros" também eram abertas. Para uma melhor organização, as questões foram separadas em quatro blocos de perguntas:

1. Perfil do entrevistado: gênero, idade, local de residência e grau de escolaridade;

2. Perfil da visita ao parque: frequência das visitas ao parque, duração da visita ao parque, meio de transporte utilizado para chegar ao parque, motivo da visita ao parque e quem acompanha quando visita o parque;

3. Avaliações da infraestrutura e serviços do parque: avaliações de 1 a 5 dos critérios utilizados na pesquisa;

4. Perguntas complementares às avaliações: busca de informações acerca do parque. 
Foram utilizados 22 critérios de avaliação nesta pesquisa, baseados nos conjuntos de infraestrutura descritos no Plano Diretor do Parque lbirapuera e nos questionários-base já mencionados. São 13 critérios acerca da infraestrutura, 5 critérios sobre as facilidades ao usuário (serviços), 2 critérios relacionados ao meio ambiente, 1 critério sobre acesso e 1 sobre a satisfação geral do usuário com o parque. Um resumo dos critérios utilizados pode ser visto no Quadro 1.

Quadro 1: Critérios utilizados para avaliação.

Frame 1: Criteria used for evaluation.

\begin{tabular}{|c|c|}
\hline Critério & Itens para Avaliação \\
\hline \multirow{13}{*}{ Infraestrutura } & Disponibilidade de bebedouros \\
\hline & Disponibilidade de lixeiras \\
\hline & Disponibilidade de equipamentos para crianças \\
\hline & Disponibilidade de equipamentos em geral \\
\hline & Disponibilidade de banheiros \\
\hline & Limpeza dos banheiros \\
\hline & Limpeza geral do parque \\
\hline & Cortesia e atendimento dos funcionários \\
\hline & Sensação de segurança nas áreas do entorno \\
\hline & Disponibilidade de assentos \\
\hline & Qualidade das calçadas \\
\hline & Qualidade e quantidade de espaços culturais \\
\hline & Qualidade da Sinalização \\
\hline \multirow{5}{*}{$\begin{array}{c}\text { Facilidades ao usuário } \\
\text { (serviços) }\end{array}$} & Quantidade e qualidade dos locais para alimentação \\
\hline & Custo-benefício dos locais para alimentação \\
\hline & Disponibilidade de vagas no estacionamento \\
\hline & Qualidade das instalações do estacionamento \\
\hline & Custo-benefício do estacionamento \\
\hline \multirow{2}{*}{ Meio ambiente } & Manutenção das áreas verdes \\
\hline & Limpeza dos lagos \\
\hline Acesso & Facilidade de acesso \\
\hline Satisfação geral & Satisfação geral com o parque \\
\hline
\end{tabular}

Fonte: elaborado pelos autores.

Source: elaborated by the authors.

Para as avaliações dos critérios foi adotada uma escala likert de 5 pontos $(1=$ péssimo $/ 2=$ ruim $/ 3=$ regular $/ 4=\mathrm{bom} / 5=$ muito bom), onde 0 respondente atribuía uma nota para cada item de avaliação. Também foi adicionada a opção "Não utilizou/não sabe avaliar" para os casos em que alguns dos itens não tenha sido utilizado na última experiência do usuário com o parque ou para casos em que o usuário não tinha opinião formada sobre o item de avaliação (BRASIL, 2018). No bloco de avaliações foi solicitado que todos os itens fossem avaliados baseados na última experiência com o parque. 


\section{Resultados e análises}

Deve-se ressaltar que as análises a seguir, feitas a partir dos resultados encontrados, dizem respeito somente à amostra e não são considerados como a representação de todos os usuários do Parque Ibirapuera, considerando que o levantamento de todos os integrantes da população pesquisada é inviável pela escassez de recursos. À vista disso, para estudos futuros, é necessário o cálculo de uma amostra estatística, por meio de procedimentos estatísticos, que seja significativa, para que assim haja possibilidade de expandir as conclusões obtidas para a totalidade do universo (GIL, 2008). Levando em consideração o tamanho da população (13 milhões de visitantes ao ano), uma margem de erro de $5 \%$ e um grau de confiança de $95 \%$, a amostra teria de estar em torno de 385 pessoas a serem entrevistadas (GIL, 2008; SÃO PAULO, 2019a).

Esta pesquisa recebeu 83 respostas válidas dentro do período de divulgação do questionário e, a partir dos resultados, com base na bibliografia encontrada, foi possível apurar e analisar questões importantes, conforme destaca Valdemarin (2010, p. 50): "na prática de pesquisa estão presentes também as apropriações, pelo pesquisador, de bibliografia de ampla circulação mobilizada para a compreensão de um determinado tema, que por sua vez, impõe significados e direcionamentos". Nesse sentido, mesmo considerando que o universo investigado não seja representativo e tenha um número reduzido de respostas, as análises se revelaram positivas e úteis a uma pesquisa futura, com um maior rigor estatístico.

\section{Perfil dos usuários da amostra}

Como explicado anteriormente, somente quem tivesse frequentado o parque em certo período podia responder ao questionário; este filtro foi feito para ser obtida uma avaliação mais condizente com a atual situação do Parque lbirapuera. O período no qual os usuários frequentaram o parque é, consequentemente, o período ao qual se refere a sua avaliação. Mais da metade dos usuários $(79,5 \%)$ que responderam ao questionário frequentaram o parque entre o final do ano de $2019-42,2 \%$ de respostas entre outubro e dezembro de 2019 - e começo de 2020 - 37,3\% de respostas entre janeiro e março de 2020 . Os outros $20,4 \%$ das respostas ficaram entre julho e setembro de 2019 (8,4\%), entre abril e junho de 2019 $(6,0 \%)$ e entre janeiro e março de 2019 (6,0\%).

Em relação ao gênero, mais da metade de quem respondeu ao questionário eram mulheres (59\%), sendo o restante da amostra dividida entre homens $(39,8 \%)$ e a categoria outros $(1,2 \%)$. Quanto à idade dos usuários da amostra, 66,3\% estão na faixa etária considerada como jovens (18 a 34 anos $)^{3}, 31,3 \%$ são adultos e 2,4\% estão na faixa etária considerada como idosos. As faixas etárias mais destacadas na amostra são as de 22 a 25 anos e de 26 a 34 anos.

No que diz respeito à residência, $77,1 \%$ dos respondentes moravam na cidade de São Paulo, enquanto $22,9 \%$ não residiam na capital. $\mathrm{Na}$ questão sobre residência, para quem morasse em São Paulo, foi solicitado 
que além do bairro o respondente também colocasse a região em que residia na capital. Sendo assim, as respostas foram agrupadas pelas cinco macrozonas administrativas de São Paulo, a saber: Norte, Sul, Leste, Oeste e Centro. A região com maior porcentagem de respondentes foi a Sul $(34,4 \%)$, onde encontra-se o Parque Ibirapuera. Quanto aos respondentes que residem fora da cidade de São Paulo, muitos $(84,2 \%)$ têm procedência de cidades do estado de São Paulo fora da região metropolitana, como é o caso de Serra Negra e Guarujá, ou de cidades da região metropolitana, como Osasco e Guarulhos. O questionário também obteve respostas vindas de outros estados, como Mato Grosso do Sul e Ceará (15,8\% da amostra).

No que se refere ao nível de escolaridade, $92,8 \%$ da amostra possuía ensino superior completo ou estava cursando o nível superior de ensino. O restante da amostra $(7,2 \%)$ possuía o ensino médio completo ou 0 ensino Fundamental II Completo. Não houve, entre os respondentes, pessoas com níveis mais baixos de escolaridade do que Fundamental II Completo.

Em resumo, o perfil da amostra é caracterizado por mulheres jovens, residentes na cidade de São Paulo e com alto nível de escolaridade. Aqui faz-se uma observação quanto aos níveis de escolaridade e de idade da amostra: o método de coleta de dados, realizado em redes sociais e por aplicativos de mensagens, pode ter influenciado a pouca variedade de respostas destas duas variáveis.

\section{Perfil da visita dos usuários da amostra}

Com relação à frequência da visita dos usuários ao Parque Ibirapuera, mais da metade dos usuários da amostra $(80,7 \%)$ não vão ao parque assiduamente, sendo que a opção "Uma vez a cada seis meses" foi a que mais se destacou, assinalada por quase metade dos respondentes $(48,2 \%)$. A segunda opção mais assinalada foi "Mensalmente" (21,7\%), seguida por "Semanalmente" (14,5\%). Quanto ao tempo de duração da visita do usuário ao parque, nenhum passou 30 minutos ou menos no lbirapuera quando o visitou, sendo que a opção "De 1 a 2 horas" foi a que mais se destacou entre as respostas (41\%). "De 2 a 3 horas" (26,5\%) e "Entre 30 minutos e 1 hora" $(12,0 \%)$ também foram uma das mais assinaladas dentre as opções da pergunta.

No tocante ao principal meio de transporte utilizado pelos usuários da amostra para chegar ao parque, 44,6\% utilizaram o transporte público ônibus $(27,7 \%)$, trem/metrô $(15,7 \%)$ e ônibus e metrô $(1,2 \%)$ - 39,8\% utilizaram veículo individual e $10,8 \%$ utilizaram meios alternativos para acessar o lbirapuera - a pé (7,2\%) e bicicleta (3,6\%). Uma resposta interessante contida na categoria outros foi a de acesso ao parque a partir do Circular Turismo SP, linha circular de ônibus turístico de São Paulo.

Sobre os motivos que levaram os respondentes a utilizar os espaços do parque, $79,5 \%$ dividiram-se entre prática de esportes ou atividades físicas $(28,9 \%)$, contato com a natureza $(27,7 \%)$ e práticas de atividades culturais e educativas $(22,9 \%)$, que são as opções que mais se aproximam das 
características gerais do lbirapuera: polo cultural e área verde no coração de São Paulo. Um resultado curioso é o uso do parque por motivações de trabalho $(1,2 \%)$, demonstrando a diversidade de motivações com as quais 0 parque é utilizado. Apesar do parque oferecer cursos gratuitos aos seus usuários, esta foi uma opção que não foi assinalada.

No que concerne às pessoas que acompanharam os usuários na visita ao parque, $37,3 \%$ vão ao parque junto com amigos, a resposta mais destacada. Outras opções assinaladas foram "Sozinho" (21,7\%), "Casal sem filhos" $(19,3 \%)$ e "Grupo familiar" (14,5\%). Outro resultado interessante, assim como na pergunta anterior, é visitar o parque acompanhado de clientes $(1,2 \%)$, o que não é totalmente inesperado, já que o lbirapuera está localizado em uma região que tem muita variedade de serviços e escritórios.

Em síntese, os usuários da amostra frequentam o Parque Ibirapuera ocasionalmente e passam de 1 a 2 horas nos espaços do parque. Apesar de não ser uma visita com duração muito longa, indica que o parque possui atrações suficientes para reter quem o utiliza por mais de 30 minutos. Transporte público é o meio de transporte mais utilizado para se ter acesso ao parque, sendo que a principal motivação é praticar esportes ou atividades físicas acompanhadas de amigos.

\section{Satisfação com a infraestrutura e serviços prestados}

Para o cálculo dos resultados foi utilizada média simples das notas dadas para cada critério de avaliação. Também foi calculado o desvio padrão para cada média, pois ele fornece uma medida de dispersão das observações ao redor da média, ou seja, ele é útil para medir a variabilidade das notas dadas.

De um modo geral, o parque foi avaliado quanto à sua infraestrutura e serviços como regular (3) pelos usuários da amostra, porém, sete critérios foram avaliados como ruins (2): disponibilidade de banheiros, disponibilidade de vagas no estacionamento, disponibilidade de bebedouros; custo-benefício do estacionamento, limpeza dos banheiros, custo-benefício dos locais para alimentação e quantidade e qualidade dos locais para alimentação (Tabela 1).

A pergunta sobre informações disponíveis sobre o parque era uma pergunta complementar do questionário, mas foi colocada junto aos demais critérios para fins de compreensão do todo da pesquisa, já que também foi solicitado ao respondente que avaliasse esse elemento. Quanto a isso, do total da amostra, 56,6\% responderam que costumavam buscar informações sobre o que o lbirapuera oferece (como eventos, serviços e infraestrutura) e $43,4 \%$ responderam que não costumavam fazer tal procedimento. 
Tabela 1: Resultados das avaliações.

Table 1: Results of evaluation.

\begin{tabular}{|l|c|c|c|}
\hline \multicolumn{4}{|c|}{ Médias de Avaliações (1 a 5) } \\
\hline \multicolumn{1}{|c|}{ Critério de Avaliação } & Frequência & Média & Desvio padrão \\
\hline Qualidade e quantidade dos espaços culturais & 73 & 3.8 & 1.08 \\
\hline Satisfação geral com o parque & 80 & 3.8 & 0.98 \\
\hline Manutenção das áreas verdes do parque & 79 & 3.7 & 1.23 \\
\hline Informações disponíveis sobre o parque & 47 & 3.6 & 0.87 \\
\hline Limpeza do parque & 80 & 3.6 & 1.13 \\
\hline Cordialidade dos funcionários do parque & 66 & 3.5 & 1.15 \\
\hline Disponibilidade de equipamentos no geral & 70 & 3.5 & 1.02 \\
\hline Limpeza dos lagos & 75 & 3.4 & 1.20 \\
\hline Disponibilidade de lixeiras & 78 & 3.4 & 1.05 \\
\hline Qualidade das calçadas & 79 & 3.4 & 1.19 \\
\hline Qualidade da sinalização & 77 & 3.3 & 1.20 \\
\hline Qualidade das instalações do estacionamento & 63 & 3.2 & 1.26 \\
\hline Disponibilidade de equipamentos para crianças & 57 & 3.2 & 1.13 \\
\hline Disponibilidade de assentos & 78 & 3.2 & 1.14 \\
\hline Acesso ao parque & 82 & 3.1 & 1.23 \\
\hline Sensação de segurança no entorno do parque & 82 & 3.1 & 1.20 \\
\hline Disponibilidade de banheiros & 78 & 2.9 & 1.18 \\
\hline Disponibilidade de vagas no estacionamento & 62 & 2.9 & 1.25 \\
\hline Disponibilidade de bebedouros & 76 & 2.9 & 1.15 \\
\hline Custo benefício do estacionamento & 61 & 2.8 & 1.32 \\
\hline Limpeza dos banheiros & 75 & 2.7 & 1.16 \\
\hline Custo benefício dos locais para alimentação & 70 & 2.5 & 1.10 \\
\hline Quantidade e qualidade dos locais para alimentação & 70 & 2.5 & 1.05 \\
\hline
\end{tabular}

Fonte: elaborado pelos autores.

Source: elaborated by the authors.

Todos os critérios utilizados para avaliar o parque obtiveram uma nota mínima de 1 (péssimo) e uma nota máxima de 5 (muito bom). Das notas dadas, apenas a satisfação geral e informações disponíveis sobre o parque não sofreram uma grande variação, comparadas às notas dos demais critérios. Praticamente todos os critérios avaliados ficaram com notas abaixo da nota dada à satisfação geral com o lbirapuera, com exceção apenas da qualidade e quantidade dos espaços culturais, que obteve a maior nota entre os critérios avaliados.

Analisando a média de avaliações por local de residência (Tabela 2), ou seja, as notas dadas pelos moradores da cidade de São Paulo e pelos não moradores da capital, as melhores notas foram dadas pelo primeiro grupo, os residentes da cidade de São Paulo. O segundo grupo, os residentes de outras cidades, melhor avaliou o custo-benefício dos locais de alimentação e o quesito informações disponíveis sobre o parque. Percebeu-se 
diferença razoável entre as notas de ambos os grupos em outros critérios, como em qualidade e quantidade dos espaços culturais, manutenção das áreas verdes, limpeza dos lagos, qualidade das calçadas e das instalações do estacionamento - todos pior avaliados por moradores de outras cidades.

Tabela 2: Média de avaliações (1 a 5) por cidade de residência

Table 2: Average ratings ( 1 to 5 ) by city of residence

\begin{tabular}{|c|c|c|c|c|c|c|c|c|c|}
\hline \multirow{2}{*}{ Critério de Avaliação } & \multicolumn{3}{|c|}{ São Paulo } & \multicolumn{3}{|c|}{ Outra cidade } & \multicolumn{3}{|c|}{ Total } \\
\hline & $\mathbf{N}$ & Méd. & DP & $\mathbf{N}$ & Méd. & DP & $\mathbf{N}$ & Méd. & DP \\
\hline Quali. e qua & 55 & 4,0 & 1,01 & 18 & 3,4 & 1,20 & 73 & 3,8 & 1,08 \\
\hline Satisfação geral com o p & 62 & 3,9 & 0,90 & 18 & 3,3 & 1,13 & 80 & 8 & 0,98 \\
\hline Manutenção das & 61 & 3,9 & 1,12 & 18 & 2,9 & ,30 & 79 &, 7 & 1,23 \\
\hline Informações disponíveis sobre o parque & 35 & 3,6 & 0,91 & 12 & 3,7 & 0,78 & 47 & 3,6 & 0,87 \\
\hline Limpeza d & 62 & 3,7 & 1,07 & 18 & 3,2 & 1,25 & 80 & 3,6 & 1,13 \\
\hline Cordialid & 49 & 3,6 & 1,11 & 17 & 3,1 & 1,22 & 66 &, 5 & 1,15 \\
\hline Dispo. de $\epsilon$ & 53 & 3,5 & 0,91 & 17 & 3,3 & 1,31 & 70 & 3,5 & 1,02 \\
\hline Limpeza o & 57 & 3,6 & 1,15 & 18 & 2,9 & 1,23 & 75 & 3,4 & 1,20 \\
\hline Disponibilid & 60 & 3,6 & 0,95 & 18 & 3,0 & 1,28 & 78 & 3,4 & 1,05 \\
\hline Quali & 61 & 3,5 & 1,19 & 18 & 2,9 & 1,11 & 79 & 4 & 19 \\
\hline Que & 59 & 3,3 & 1,21 & 18 & 3,2 & 1,20 & 77 & 3,3 & 1,20 \\
\hline $\begin{array}{l}\text { Qua } \\
\text { esta }\end{array}$ & 45 & 3 & 8 & 18 & 2 & 1, & 63 & 3 & 1 \\
\hline Dispo. d & 40 & 3,2 & 0,97 & 17 & 3,1 & 1,45 & 57 & 3,2 & 1,13 \\
\hline Dispo. c & 60 & 3,2 & 1,12 & 18 & 3,1 & 1,23 & 78 & 2 & 1,14 \\
\hline Acesso ao parque & 63 & 32 & 1,17 & 19 & 2,7 & 1,38 & 82 & 3,1 & 1,23 \\
\hline $\begin{array}{l}\text { Sensação de segur } \\
\text { parque }\end{array}$ & 63 & 3,2 & 2 & 19 & 2,7 & 1,10 & 82 & 3,1 & 1,20 \\
\hline Disponibilidade de banheiros & 100 & 3,0 & 0 & 18 & 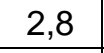 & 1,15 & 8 & 2,9 & 1,18 \\
\hline $\begin{array}{l}\text { Disponibilidade de vagas no } \\
\text { estacionamento }\end{array}$ & 44 & 3,1 & 1,30 & 18 & 2,6 & 1,09 & 62 & 2,9 & 1,25 \\
\hline Disponibilidade de bebedouro & 58 & 2 , & 1,13 & 18 & 2,8 & 1,22 & 76 & 9 & 1,15 \\
\hline Custo benefício do estaci & 42 & 2,9 & 1,35 & 19 & 2,4 & 1,22 & 61 & 2,8 & 1,32 \\
\hline Limpeza dos banheiros & 58 & 2,8 & 1,21 & 17 & 2,4 & 0,93 & 75 & 2,7 & 1,16 \\
\hline $\begin{array}{l}\text { Custo benefício dos locais para } \\
\text { alimentação }\end{array}$ & 52 & 2,5 & 6 & 18 & 2,6 & 1,24 & 70 & 2,5 & 1,10 \\
\hline $\begin{array}{l}\text { Quantidade e qualidade dos loca } \\
\text { alimentação }\end{array}$ & 52 & 2,5 & 1,02 & 18 & 2,5 & 1,15 & 70 & 2,5 & 1,05 \\
\hline
\end{tabular}

Fonte: elaborado pelos autores.

Source: elaborated by the authors.

Por fim, em resumo, de acordo com os resultados encontrados na pesquisa, a infraestrutura e os serviços do Parque Ibirapuera foram avaliados pelos usuários da amostra como regular, sendo que o critério que obteve maior nota foi a qualidade e quantidade dos espaços culturais, com avaliação média de 3,8. Apesar de ser considerado o melhor parque de São Paulo, o Ibirapuera não conseguiu obter notas no intervalo entre bom ou muito bom em nenhum dos critérios avaliados, sendo que 30,4\% dos critérios obtiveram média inferior aos demais, avaliados como regulares. Dos critérios avaliados como ruins, os serviços relacionados à alimentação dentro do parque foram os que obtiveram as piores notas. 


\section{Considerações finais}

Esta pesquisa teve como foco geral de investigação a satisfação do usuário de parques urbanos com sua infraestrutura e serviços prestados, para isso foi escolhido o Parque Ibirapuera como objeto de estudo. Os objetivos gerais e específicos foram atingidos a partir da aplicação de questionário junto a usuários do parque e da análise dos resultados encontrados.

O lbirapuera é considerado o mais conhecido e um dos melhores parques presentes na cidade de São Paulo. Sua presença é marcante no turismo de São Paulo, pois é divulgado como um dos atrativos turísticos da cidade, sendo também um dos mais visitados. Sendo assim, é importante não apenas no sentido de avaliar a qualidade de um atrativo turístico, mas também no sentido de avaliar um espaço de lazer para a população - medir a satisfação dos usuários do parque com aquilo que é ofertado a eles durante a visita, seja a infraestrutura seja outras facilidades, como serviços.

A gestão da qualidade não é algo restrito apenas aos ambientes de negócios e a empresas voltadas à venda de produtos ou que trabalhem com serviços, mas também é relevante nos espaços públicos utilizados pelas pessoas de um ambiente urbano. Pode-se dizer que uma das premissas do turismo é que se um local está adequado para o uso dos moradores locais, então também estará apto para atender as necessidades de um turista.

Apesar do tipo de coleta de dados não permitir fazer generalizações, como um estudo preliminar esta pesquisa descobriu alguns dados interessantes acerca da avaliação do parque por parte de seus usuários. Embora seja considerado o melhor parque da capital, ainda há aspectos mal avaliados e que precisam ser trabalhados para um melhor atendimento das necessidades de quem o frequenta. É difícil dizer que os aspectos que se apresentaram como positivos não precisam ser trabalhados, pois todos foram avaliados como regulares, ainda mais quando não há um padrão de qualidade para os parques da capital paulista.

Quanto ao questionário utilizado, os parques urbanos possuem infraestruturas e tamanhos diferentes, portanto, para aplicação em outros tipos de parque, o ideal seria fazer questionários padrão por tipologias e acompanhar os resultados ao longo de um período de tempo para identificar possíveis melhorias nos critérios utilizados para avaliação, criando assim um indicador para cada tipo específico de parque.

Não foi possível a aplicação de um maior rigor estatístico nesta pesquisa, mas esse é um processo importante a ser feito, pois torna a amostra mais confiável quanto à aleatoriedade da coleta de dados. Outro procedimento importante é verificar a diferença de avaliações entre os dias da semana - pois o parque recebe diferentes fluxos de pessoas dependendo do dia da semana, sendo que os finais de semana são os dias com maior fluxo de usuários - , assim como a diferença de avaliação entre os períodos do dia: um usuário que frequenta o parque de manhã cedo pode avaliá-lo de modo diferente daquele usuário que o visita à tarde ou à noite. 
Esta pesquisa contribui para a discussão sobre a qualidade das áreas verdes voltadas ao lazer e à recreação disponível para o uso da população - como é o caso dos parques urbanos - da cidade de São Paulo. Essa discussão se faz importante no âmbito do turismo pois é uma atividade que pode usar estes espaços para aumentar a oferta de atrativos turísticos de uma localidade. Longe de esgotar as possibilidades de pesquisa referente ao tema, esta pesquisa avançou na temática no sentido de elencar critérios relacionados a esses locais e colocá-los para a avaliação daqueles que mais usufruem de seus espaços: os usuários. Isto é algo que ainda não é totalmente explorado, tanto pela academia quanto pelo poder público.

\section{Referências}

AMERICAN SOCIETY FOR QUALITY (ASQ). Quality glossary of terms, acronyms \& definitions. Disponível em: https://asq.org/qualityresources/quality-glossary. Acesso em: 16 abr. 2020.

ÁREAS VERDES DAS CIDADES. Parques em São Paulo e Região Metropolitana resenhados pelo Áreas Verdes das Cidades. Disponível em: $\quad$ https://www.areasverdesdascidades.com.br/2006/11/areas-verdesurbanas-por-zonas-e.html. Acesso em: 23 abr. 2020.

ASSOCIAÇÃO BRASILEIRA DE NORMAS TÉCNICAS (ABNT). NBR ISO 9000: sistemas de gestão de qualidade - fundamentos e vocabulários. [S.I.], 2015. Projeto de revisão, ABNT/CB-025.

CORPORATE FINANCE INSTITUTE (CFI). What is public infrastructure? Disponível em: https://corporatefinanceinstitute.com/resources/knowledge/ economics/public-infrastructure/. Acesso em: 16 abr. 2020.

CHAPPELOW, J. Infrastructure. In: Investopedia. Disponível em: https://www.investopedia.com/terms/i/infrastructure.asp. Acesso em: 16 abr. 2020.

BRASIL. Ministério do Meio Ambiente. Parques e áreas verdes. Disponível em: $\quad$ https://www.mma.gov.br/cidades-sustentaveis/areas-verdes-urbanas/ item/8051.html. Acesso em: 07 fev. 2020.

BRASIL. Ministério dos Transportes, Portos e Aviação Civil. Secretaria Nacional de Aviação Civil. Pesquisa de desempenho operacional e satisfação do passageiro: metodologia. 2018. Disponível em: https://www.gov.br/infraestrutura/pt-br/centrais-de-conteudo/metodologia 2018 - v-0-0.pdf. Acesso em: 16 abr. 2020.

CIANGA, N.; POPESCU, A. C. Green spaces and urban tourism development in Craiova municipality in Romania. European Journal of Geography, [S.I.], vol. 4, n. 2, p. 34-45, 2013.

EUROPEAN ENVIRONMENT AGENCY. Glossary for urban green infrastructure. Disponível em: https://www.eea.europa.eu/themes/sustainability-transitions/urban-environ ment/urban-green-infrastructure/glossary-for-urban-green-infrastructure. Acesso em: 30 abr. 2020. 
EDUCAÇÃO E TERRITÓRIO. Direito à cidade. Disponível em: https://educacaoeterritorio.org.br/glossario/direito-a-cidade/. Acesso em: 12 maio 2020.

FUNDAÇÃO ARON BIRMANN (FAB). Indicador de parques urbanos. Disponível em: https://www.fundacaoaronbirmann.org.br/publicacoes/ abrir/indicador-parques-urbanos-2019. Acesso em: 08 maio 2020.

GIL, A. C. Métodos e técnicas de pesquisa social. 6 ed. São Paulo: Atlas, 2008. Disponível em: https://ayanrafael.files.wordpress.com/2011/08/gil-a-cmc3a9todos-e-tc3a9cnicas-de-pesquisa-social.pdf. Acesso em 26 abr. 2020.

GUZZO, P.; CARNEIRO, R.; JúNIOR, H. Cadastro Municipal de espaços livres urbanos de Ribeirão Preto (SP): acesso público, índices e base para novos instrumentos e mecanismos de gestão. Revista da Sociedade Brasileira de Arborização Urbana. vol. 1, n. 1, p. 19-30, 2006.

INSTITUTO BRASILEIRO DE GEOGRAFIA E ESTATÍSTICA (IBGE). Comissão Nacional de Classificação. Disponível em: https://cnae.ibge.gov.br/?view=estrutura\&tipo=cnae\&versao classe $=7.0 .0 \& \mathrm{v}$ ersao subclasse=9.1.0. Acesso em: 26 abr. 2020.

INTERNATIONAL FEDERATION OF PARKS AND RECREATION ADMINISTRATION (Ifpra). Benefits of Urban Parks: a systematic review. Copenhagen and Alnarp, 2013. Disponível em: https://www.theparksalliance.org/benefits-of-urban-parks-a-systematic-review -a-report-for-ifpra-published-in-january-2013/. Acesso em: 12 mar. 2020.

KOTLER, P.; KELLER, K. L. Marketing para o século XXI. In: KOTLER, P.; KELLER, K. L. Administração de marketing. 14 ed. São Paulo: Pearson Education do Brasil, 2012. cap. 1, p. 1-34. Tradução Sônia Midori Yamamoto; revisão técnica Edson Crescitelli.

KOTLER, P.; KELLER, K. L. Criação de relações de longo prazo baseadas em fidelidade. In: KOTLER, P.; KELLER, K. L. Administração de marketing. 14 ed. São Paulo: Pearson Education do Brasil, 2012. cap. 5, p. 129-162.

KOTLER, P.; KELLER, K. L. Desenvolvimento e gerenciamento de serviços. In: KOTLER, P.; KELLER, K. L. Administração de marketing. 14 ed. São Paulo: Pearson Education do Brasil, 2012. cap. 13, p. 381-410. Tradução Sônia Midori Yamamoto; revisão técnica Edson Crescitelli.

MACEDO, S. S.; SAKATA, F. G. Parques urbanos no Brasil. 3. ed. São Paulo: Editora da Universidade de São Paulo, 2010. Disponível em: http://quapa.fau.usp.br/wordpress/parques-urbanos-no-brasil/. Acesso em: 23 dez. 2019.

MOSAHAB, R.; MAHAMAD, O.; RAMAYAH, T. Service Quality, Customer Satisfaction and Loyalty: a test of mediation. International Business Research, [S.I.], vol. 3, n. 4, p. 72-80, 2010.

PAULA, D. de. Usos e desusos de parques urbanos contemporâneos: estudo de caso parque da Cidade - Serra/ ES. 2017. 278 f. Dissertação (Mestrado em Cidade e Impactos no Território) - Centro de Artes, Universidade Federal do Espírito Santo, Espírito Santo, 2017. Disponível em: http://repositorio.ufes.br/handle/10/10066. Acesso em: 26 jan. 2020. 
RAIMUNDO, S.; SARTI, A. C. Parques urbanos e seu papel no ambiente, no turismo e no lazer da cidade. Revista Iberoamericana de Turismo, Penedo, vol. 6, n.2, p. 3-24, 2016.

ROSSI, C. A.; SLONGO, L. A. Pesquisa de satisfação de clientes: o estadoda-arte e proposição de um método brasileiro. Revista de Administração Contemporânea, v. 2, n. 1, p. 101-125, 1998.

SÃO PAULO (Estado). Secretaria de Infraestrutura e Meio Ambiente. Parque urbano. Disponível em: https://www.infraestruturameioambiente. sp.gov.br/parque-urbano/. Acesso em: 08 fev. 2020.

SÃO PAULO (Cidade). Secretaria Municipal de Desenvolvimento Urbano (SMDU). Caderno das subprefeituras: material de apoio para revisão participativa dos planos regionais das subprefeituras (subprefeitura de Vila Mariana). 2016a. Disponível em: https://gestaourbana.prefeitura.sp.gov.br/ marco-regulatorio/planos-regionais/arquivos/. Acesso em: 08 maio 2020.

SÃO PAULO (Cidade). Secretaria Municipal de Desenvolvimento Urbano (SMDU). Caderno de propostas dos planos regionais das subprefeituras: quadro analítico (Vila Mariana). 2016b. Disponível em: https://gestaourbana.prefeitura.sp.gov.br/marco-regulatorio/planosregionais/arquivos/. Acesso em: 08 maio 2020.

SÃO PAULO (Cidade). Secretaria Municipal do Verde e Meio Ambiente (SVMA). Parque Ibirapuera: plano diretor. 2019a. Disponível em: https://www.parqueibirapuera.org/arquivos/pd/proposta plano diretor comp actada.pdf. Acesso em: 23 dez. 2019.

SÃO PAULO (Cidade). São Paulo Turismo/ Visite São Paulo. São Paulo: cidade do mundo (dados e fatos dos eventos, viagens e turismo na capital paulista). 2019b. Disponível em: http://www.observatoriodoturismo.com.br/ category/estudos-e-publicacoes/. Acesso em: 08 maio 2020.

SÃO PAULO (Cidade). Secretaria Municipal do Verde e Meio Ambiente (SVMA). Programação de eventos Parque Ibirapuera. 2019c. Disponível em: https://www.prefeitura.sp.gov.br/cidade/secretarias/upload/Programacao Eventos Ibirapuera ABRIL 2019(1).pdf. Acesso em: 08 maio 2020.

SAKATA, F. G. Parques urbanos no Brasil - 2000 a 2017. 2018. 348 f. Tese (Doutorado em Paisagem e Ambiente) - Faculdade de Arquitetura e Urbanismo, Universidade de São Paulo, São Paulo, 2018. Disponível em: https://www.teses.usp.br/teses/disponiveis/16/16135/tde-20092018-

143928/pt-br.php. Acesso em: 23 dez. 2019.

SAMPAIO, P. R.P; SAMPAIO, R. S. R; MAGALHÃES, L. Questões jurídicas relevantes na gestão de parques urbanos no Brasil: panorama geral e estudo de caso do Parque do Flamengo. Revista de Direito Administrativo, Rio de Janeiro, v. 272, p. 339-379, 2016.

SERVIÇO SOCIAL DO COMÉRCIO (Sesc). A importância da qualidade espacial dos espaços públicos para a concretização do lazer como um direito social. Anais do Encontro Nacional de Recreação e Lazer - ENAREL, Minas Gerais: Sesc Estalagem Ouro Preto, 2013. eletrônicos.... Disponível em: http://www.sesc.com.br/portal/site/Enarel/anais/posters/Mesas/Mesa+ 05/. Acesso em: 24 abr. 2020. 
SILVA, M.; VALDEMARIN, VT., org. Pesquisa em educação: métodos e modos de fazer [online]. São Paulo: Editora UNESP; São Paulo: Cultura Acadêmica, 2010. 134 p. ISBN 978-85- 7983-129-4.

SILVEIRA, D. T.; CÓRDOVA, F. P. A Pesquisa Científica. In: GERHARDT, T. E.; SILVEIRA, D. T. (org.). Métodos de Pesquisa. Porto Alegre: Editora da UFRGS, 2009. cap. 2, p. 31-42.

ZMITROWICZ, W; NETO, G. de A. Infraestrutura Urbana. Texto Técnico. PCC-POLI-USP. São Paulo, 1997. Disponível em: http://www.pcc.usp.br/files/text/publications/TT 00017.pdf. Acesso em: 17 abr. 2020.

\section{Notas}

${ }^{1}$ Foi adotado o termo organização ao invés de empresa nesta pesquisa, pois é mais abrangente, como consta na ABNT ISSO 9000:2015. Para casos em que os autores utilizaram o termo empresa, este foi mantido, como forma de não retirar a ideia original.

2 Devido à pandemia de COVID-19, os parques de São Paulo foram fechados ao público a partir do dia 21 de março de 2020 e, desse modo, não foi possível realizar entrevistas presenciais.

${ }^{3} \mathrm{O}$ IBGE considera jovens as pessoas entre 15 e 29 anos.

Agradecimentos: Artigo derivado de Trabalho de Conclusão de Curso da Escola de Comunicações e Artes da Universidade de São Paulo (ECA-USP).

Daiane Uinnes Faustino: Universidade de São Paulo, São Paulo, SP, Brasil.

E-mail: daiane.faustino@alumni.usp.br

Reinaldo Miranda de Sá Teles: Universidade de São Paulo, São Paulo, SP, Brasil.

E-mail: reiteles@usp.br

Link para o currículo Lattes: http://lattes.cnpq.br/5662794770689990

Data de submissão: 22 de outubro de 2020

Data de recebimento de correções: 01 de maio de 2021

Data do aceite: 01 de maio de 2021

Avaliado anonimamente 